\title{
Breath Holding
}

National Cancer Institute

\section{Source}

National Cancer Institute. Breath Holding. NCI Thesaurus. Code C121558.

Episodic apnea, which is more common in young children and usually resolves by age six. 